\title{
As interfaces do ambiente para a saúde: um estudo com crianças
}

\author{
Environmental interfaces in health: a study of school agers \\ Las interfaces del ambiente para la salud: un estudio con niños
}

\author{
Arina Fonseca'; Fátima Helena do Espírito Santo ${ }^{\text {II }}$, Lina Márcia Miguéis BerardinelliII; \\ Rose Mary Costa Rosa Andrade Silva ${ }^{I V}$
}

\begin{abstract}
RESUMO: O estudo objetivou analisar o conhecimento de crianças sobre vida saudável, o que pode torná-las corresponsáveis pela própria saúde. Trata-se de pesquisa qualitativa, descritiva do tipo pesquisa-ação, em que foram entrevistadas 19 crianças de 7 a 12 anos em uma Policlínica Militar do município de Niterói/RJ. Durante a consulta de enfermagem, foi realizada entrevista semiestruturada, entre os meses de agosto e setembro de 2013. Os dados foram coletados e submetidos à análise de conteúdo de Bardin, seguida por categorização. Os resultados demonstraram que as crianças possuem conhecimentos capazes de fomentar uma vida baseada em comportamentos saudáveis, mas, para isto, é necessário incentivo e ações de profissionais que gerem interfaces de relações produtivas com as crianças. Concluiu-se que o enfermeiro pode ser o mediador destas interfaces e contribuir para a autonomia das crianças na corresponsabilidade para desenvolvimento de hábitos saudáveis. Palavras-Chave: Enfermagem; crianças; comportamentos saudáveis; autonomia e corresponsabilidade.
\end{abstract}

ABSTRACT: This qualitative, descriptive study used action-research to ascertain children's knowledge of healthy living that can make them co-responsible for their own health. In August and September 2013, during nursing appointments at a Military Medical Clinic in Niteroi/RJ, Brazil, 19 schoolchildren from 7 to 12 years old took part in semi structured interviews. The data were subject to Bardin's content analysis, followed by categorization. The results showed that children have knowledge able to foster a life based on healthy behavior; that, however, requires incentives and professional action to build productive relationship interfaces with the children. It was concluded that nurses can mediate at these interfaces and contribute to children's autonomy in co-responsibility for developing healthy habits.

Keywords: Nursing; children; healthy behaviors; autonomy and co-responsibility.

RESUMEN: El estudio tuvo como objetivo analizar el conocimiento de los niños sobre la vida saludable que puede hacerlos corresponsables de su propia salud. Se trata de una investigación cualitativa, descriptiva, de tipo investigación-acción, donde 19 niños de 7 a 12 años de edad fueron entrevistados, en una Clínica Militar de Niterói/RJ, Brasil. Durante la consulta de enfermería, se realizaron entrevistas semiestructuradas entre los meses de agosto y septiembre 2013. Los datos recolectados fueron sometidos al análisis de contenido de Bardin, seguido de categorización. Los resultados mostraron que los niños tienen los conocimientos capaces de fomentar una vida basada en comportamientos saludables, pero, para esto, hace falta incentivos y acciones de profesionales que generen interfaces de las relaciones con los niños. Se concluyó que lo enfermero puede ser el mediador de estas interfaces y contribuir a la autonomía del niño en la corresponsabilidad en cuanto al desarrollo de hábitos saludables.

Palabras Clave: Enfermería; niños; conductas saludables; autonomía y corresponsabilidad.

\section{INTRODUÇÃO}

A Organização Mundial da Saúde (OMS) descreve a situação alarmante sobre doenças crônicas não transmissíveis (DCNT) cuja incidência aumenta, tanto em países desenvolvidos quanto em desenvolvimento, em pessoas de todas as idades. As principais DCNT são as cardiovasculares, o diabetes, alguns tipos de câncer e doenças respiratórias.
As principais causas das DCNT estão bem estabelecidas: tabagismo, ingestão de bebidas alcoólicas, sedentarismo, alimentação não saudável e obesidade ${ }^{1}$. Estes são alguns dos fatores de risco modificáveis comuns para as principais DCNT, ou seja, hábitos ou comportamentos transformáveis, antes que causem danos à saúde do indivíduo.

\footnotetext{
'Enfermeira do Hospital Central Aristarcho Pessoa. Mestre em Enfermagem. Niterói, Rio de Janeiro, Brasil. E-mail: arinafonseca@hotmail.com.

"Enfermeira. Doutora em Enfermagem. Professora Associada do Departamento de Enfermagem Médico-Cirúrgica e da Escola de Enfermagem Aurora de Afonso Costa da Universidade Federal Fluminense. Niterói, Rio de Janeiro, Brasil. E-mail: fatahelen@hotmail.com.

IIIEnfermeira. Doutora em Enfermagem. Professora Adjunta do Departamento de Enfermagem Médico-Cirúrgica da Faculdade de Enfermagem da Universidade do Estado do Rio de Janeiro.Brasil. E-mail: 1.m.b@uol.com.br.

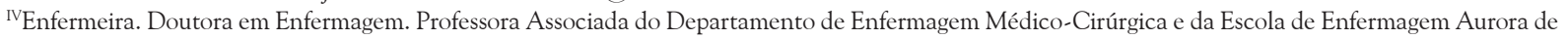
Afonso Costa da Universidade Federal Fluminense. Niterói, Rio de Janeiro, Brasil. E-mail: roserosauff@gmail.com.
} 
As ações de promoção da saúde visando à redução das taxas de morbimortalidade por DCNT são baseadas na diminuição da exposição aos fatores de risco modificáveis e a educação em saúde é uma ferramenta para a prática da promoção da saúde neste âmbito.

Entre objetivos, metas e ações elaboradas pelo Plano de Ações Estratégicas para o Enfrentamento das DCNT 2011-2022², em parceria entre Ministérios e liderada pelo Ministério da Saúde (MS), a criança é visada como foco de atenção. Apesar de não ser uma política centrada na atenção à saúde da criança, tem suma importância e possibilita alcançar objetivos propostos pela Agenda de Compromissos para a Saúde Integral da Criança e a diminuição da mortalidade infantil, que apresenta os cuidados com a saúde infantil como essenciais para o MS e enfatiza o cuidado integral e multiprofissional ${ }^{2,3}$.

Os fatores de risco modificáveis integram o grupo de fatores de risco individuais, mas isto não significa que as ações para diminuição da exposição ao risco sejam de cunho individual. Para enfrentar o problema, é necessário conhecer os ambientes no qual este indivíduo está inserido, quais conceitos já estão estabelecidos em sua vida e possíveis formas de colaborar na formação de comportamentos saudáveis.

A educação em saúde, neste contexto, deve ser entendida como mobilizadora da participação social porque as verdadeiras práticas educativas somente têm lugar entre sujeitos sociais, com caráter emancipador, participativo, criativo e dialógico, contribuindo para a autonomia do cidadão .

Diante do exposto, o presente estudo objetivou: analisar o conhecimento de crianças sobre vida saudável, o que pode torná-las corresponsáveis pela própria saúde.

\section{ReFERENCIAL TEÓRICO}

O conceito de ambiente proposto no Modelo de Promoção da Saúde de Nola Pender ${ }^{5}$, bem como o empowerment ${ }^{6}$, conceito estruturante da promoção da saúde, foram utilizados na análise. Pender define ambiente como o contexto social, cultural e físico no qual a vida se desenvolve, podendo ser manipulado pelo indivíduo para criar uma conjuntura positiva para comportamentos benéficos à saúde. Interfaces com família e colegas de escola colaboram, determinando normas e modelos a seguir, em crenças e em atitudes relacionadas ao engajamento a determinado comportamento de saúde?

Oempowerment, em português empoderamento ${ }^{6}$, possibilita aos indivíduos, de forma particular e coletiva, um aprendizado que os capacita a viver todas as etapas de vida, lidando com restrições impostas pelas enfermidades eventuais ${ }^{6}$.

Pensamentos de autores como Paulo Freire ${ }^{8}$ e Merleau-Ponty ${ }^{9}$ também foram utilizados para anali- sar e compreender o aprendizado e o mundo infantil, desde sua própria perspectiva.

Na pedagogia de Freire, a liberdade é essencial para a prática educativa, só alcançando efetividade e eficácia com a participação livre e crítica dos indivíduos $^{8}$. Já Merleau-Ponty ${ }^{9}$ afirma que a apreensão de uma significação se faz pelo corpo e, assim, quando a criança se habitua a distinguir duas cores, por exemplo, constata-se que o hábito adquirido está beneficiando a distinção de outras cores. Portanto, o organismo da criança modifica-se antes da influência do meio como forma de pré-adaptação para se estabilizar ao meio e desenvolver suas potencialidades, existindo uma reciprocidade entre estímulo e meio.

\section{Metodologia}

Trata-se de uma pesquisa qualitativa, descritiva do tipo pesquisa-ação, realizada no município de Niterói/RJ, em uma Policlínica Militar, cujos sujeitos foram selecionados de acordo com os seguintes critérios de inclusão: crianças com idade entre 7 e 12 anos, demonstrando capacidade de compreensão, independente de sexo, etnia, crença religiosa, com autonomia para responder a todas as perguntas e manifestar o desejo de participar voluntariamente.

Os critérios de exclusão foram crianças com idades diferentes das estipuladas, sem autonomia para participar e responder às questões. Utilizou-se a terminologia criança, segundo os dispositivos da lei, considerando pessoa até 12 anos de idade incompletos e adolescentes, aqueles entre 12 e 18 anos $^{10}$. De igual maneira, essa terminologia também é considerada nos Descritores em Ciências da Saúde (DeCS) ${ }^{11}$. As crianças que aceitaram participar das consultas de enfermagem foram autorizadas pelos responsáveis.

O estudo foi desenvolvido segundo o preconizado na legislação vigente sobre pesquisas envolvendo seres humanos ${ }^{12}$, sendo aprovado pelo Comitê de Ética em Pesquisa (CEP) do Hospital Universitário Antônio Pedro da Universidade Federal Fluminense sob o Parecer $n^{\circ} 411723$.

Quanto aos depoimentos obtidos, foi observado o anonimato dos sujeitos, os quais receberam denominações de personagens da literatura e filmes infantis, seguidas das respectivas idades.

Os dados foram submetidos à análise de conteúdo segundo Bardin ${ }^{13}$, seguindo as etapas: pré-análise, na qual foi sistematizado o corpus de análise, leitura flutuante e exaustiva, seguindo-se de exploração do material e tratamento dos resultados, inferências e interpretação.

Em seguida, foram identificados os conteúdos relevantes, ou seja, os trechos que marcaram os depoimentos por serem similares ou diferentes. Após a identificação das unidades de registro (UR), os dados 
foram agrupados por convergência de conteúdos, emergindo as seguintes categorias analíticas: Entre o ideal e o real e As interfaces do ambiente para a saúde.

Neste artigo, será abordada a segunda categoria, que possui quatro subcategorias para responder ao objetivo em questão: Família e escola; Saúde como ausência de doença; Movimentos de mudança; e $\mathrm{O}$ brincar.

\section{Resultados e Discussão}

Entre as interfaces identificadas nas falas das crianças, são marcantes família e escola, fato relativo à idade dos depoentes, que têm, nestes ambientes, a possibilidade de adquirir conhecimentos. Os conhecimentos produzidos levam à formação de conceitos sobre saúde e doença e, quando estimuladas por outros indivíduos ou conceitos, levam ao desenvolvimento do pensamento crítico capaz de criar e recriar ações segundo seu próprio julgamento. Dão-se, aí, os movimentos de mudança. Por fim, o brincar, atividade inerente ao ser criança, é percebido em unidades de contexto que expressam brincadeira como forma de manutenção do ser saudáve ${ }^{14}$. $O$ brincar representa a imaginação em ação e é fruto das relações humanas, portanto oriundo das interfaces de relacionamento que o indivíduo criança possui.

\section{Família e escola}

Os resultados mostram que as crianças expressam comportamentos espelhados nos comportamentos dos pais ou de outro familiar, ratificando-se a importância familiar na construção de bons hábitos de saúde:

Meu pai está querendo me ensinar futevôlei [...] que ele ensinou minha irmã [...]. Minha irmã já sabe, ele quer me ensinar, sem ele eu não consigo. (Fiona, 10 anos)

Não sei, minha mãe disse que é bom, carne branca [...] (Sininho, 13 anos)

O ambiente é definido como o contexto social, cultural e físico no qual a vida se desenvolve, podendo ser manipulado pelo indivíduo para criar uma conjuntura positiva nos comportamentos benéficos à saúde. Influências interpessoais, como família, colegas de escola ou trabalho, colaboram, determinando normas e modelos a seguir e crenças e atitudes relacionadas ao engajamento a determinado comportamento de saúde?

As influências das interfaces com pessoas presentes no ambiente e não na estrutura familiar devem ser consideradas, como, por exemplo, uma empregada:

[...] a Cátia não cozinha bem aí enche de sal e margarina na comida, agora mamãe está dando uma olhada, está diminuindo o meu colesterol. (Pequena Sereia, 7 anos)

A mãe é, na maioria das famílias, a principal responsável pelos ensinamentos no cuidado corporal. $\mathrm{O}$ pai tem papel similar; ambos são os primeiros educadores e transmitem representações culturais, valores e crenças marcantes para o escolar por envolverem afeto $^{8}$. A associação de emoções positivas ao comportamento de saúde aumenta a probabilidade de compromisso com a ação em questão ${ }^{5,7}$.

E eu também fico o dia inteiro vendo TV, jogando videogame, também meus pais não me deixam sair de casa pra brincar lá fora. (Wolverine, 9 anos)

$\bigcirc$ poder de decisão parental sobre a vida dos filhos pode ser responsável por comportamentos inapropriados à boa saúde.

Famílias de crianças obesas são consideradas um importante agente de prevenção ou manutenção da condição de obesidade, pois desempenham significativo papel na educação alimentar da criança e influenciam no sentido de terem ou não hábitos saudáveis em suas rotinas ${ }^{15}$.

Minha prima está um pouco acima do peso [...] Aí ela foi no nutricionista. A minha avó estava dando um pouco de comida pra ela... aí depois ela passou a comer devagar e começou a se equilibrar. (Minnie Mouse, 10 anos)

Identificando o problema da colega, esta menina dá resposta à questão da obesidade: o equilíbrio. Seres humanos interagem com seu ambiente, buscando moldá-lo para satisfazer suas necessidades ${ }^{5,16}$. Desse modo, a compreensão do problema alheio pode ajudar numa reflexão crítica, moldando seu ambiente positivamente para o próprio comportamento saudável.

Estudos descrevem que hábitos de atividade física podem ser influenciados fortemente pela escola, coadjuvante na formação de hábitos de vida e comportamentos de saúde, porque crianças e adolescentes passam grande parte dos seus dias dentro dela ${ }^{17}$.

[...] às vezes, tem alguns esportes que nos ajudam até

[...] tipo na escola. (Fred Flintstone, 9 anos)

Então, a escola é outra interface desencadeante dos comportamentos de saúde, embora, neste caso, sentimentos de afeto e amor não surjam da mesma forma que em família.

No Modelo de Promoção da Saúde de Pender, comportamentos anteriores e crenças adquiridas são fatores que afetam a construção de comportamentos de saúde e, consequentemente, a promoção da saú$\mathrm{de}^{18}$. Aqui, conhecimentos adquiridos na escola são primordiais. Quando indagada sobre o que faz bem...

Ir para escola, [...] ir para uma educação física, ir para ginástica olímpica, brincar no recreio e brincar com meus brinquedos no recreio no dia da novidade. (Pequena Sereia, 7 anos)

Os indivíduos, diante de sua complexidade biopsicossocial, tendem a interagir com o ambiente, transformá-lo, progressivamente, e serem transformados ao passar do tempo $0^{5,16,18,19}$. Assim, crianças intera- 
gem intensamente com seus ambientes, os quais, em grande parte do tempo, são compostos pela família e pela escola, sofrendo modificações e modificando-os com suas indagações curiosas e afirmativas inocentes, mas regadas de verdade.

\section{Saúde como ausência de doença}

No início do século XX, a saúde era entendida como ausência de doenças e as ações governamentais de promoção da saúde eram centradas no controle das enfermidades. Em 1948, a OMS definiu saúde como "o completo estado de bem-estar físico, mental e social, e não simplesmente a ausência de doença" 20:65. Considerado um conceito utópico, doravante devia ser seguido como meta a ser alcançada.

Atualmente, diversos autores entendem a saúde mais dinamicamente, como um processo de construção permanente de cada indivíduo e da coletividade ${ }^{2,4,6}$.

O escolar demonstra fortemente o conceito de saúde como ausência de doença, ou seja, para ele, recebendo medicamento passou a ter saúde:

[...] eu fui lá no médico, aí graças a Deus não me deu benzetacil, né? Me deu um remédio, aí eu fui tomando, tomando e melhorei. Então o remédio faz bem também. (Docinho, 9 anos)

Esta concepção vinculada à doença faz a criança conectar ser saudável a ações medicalizadoras:

As vacinas em dia, ir ao médico pelo menos uma vez por mês, por semana e se precisar tomar remédio. (Florzinha, 9 anos)

Considerando a definição de saúde da $\mathrm{OMS}^{20}$, nenhum ser humano é totalmente saudável. Entretanto, a situação de saúde passa por uma série interações na complexidade da vida individual e coletiva ao longo da existência. Não sendo um estado estável, ela é influenciada, constantemente, pelo modo de cuidar do próprio corpo, pelas relações interpessoais, pelo trabalho, além de outros ambientes e relações que interferem na dinâmica pessoal.

Por seu alto grau de subjetividade e determinação histórica, indivíduos e sociedades consideram saúde a partir de momentos vivenciados, de valores e/ou das necessidades que enfrentam ${ }^{20}$. No caso do escolar, este trânsito entre realidade e imaginação ${ }^{3}$ colabora para a visão da saúde como oposta à doença e para a valorização das doenças que, por vezes, ouvem falar:

Eu já ouvi falar em hepatite, só que eu não sei o que causa isso. [...]. Hum, hum. Gripe suína [Risos]. (Shrek, 11 anos)

Este estudo permite entender o ponto de vista do escolar através de uma atitude de agachamento, que vai ao encontro da criança mais próxima ao chão, no mundo em que habita ${ }^{21}$, de forma quase ingênua, verificando que muitas das falas apresentadas podem ter relação com as experiências vividas ou conhecidas, as interfaces.

A analogia entre os hábitos saudáveis e a presença de DCNT apareceu em algumas falas; portanto, para algumas análises, é necessário valorizar o contexto imaginativo do escolar.

[...] se você comer muita massa e muito doce, você vai acabar ficando com muito açúcar no sangue [...] quando a gente come muita fritura, acaba indo gordura para o coração [...]. (Minnie Mouse, 10 anos)

O neologismo formado demonstra uma fusão entre o ser guloso e o estado de obesidade. Pode-se interpretar que, na imaginação desta criança, o ato de comer muito, ou seja, o ser guloso ${ }^{22}$, tem como consequência a obesidade:

É o nome da doença que dá se a gente ficar comendo besteira? É a gente fica gordo [...] eu lembro só que eu esqueci. Não. [...]. Gulosidade???? É obesidade. Você não fica bem da saúde. É [...] gordo. Problema no coração. (Pernalonga, 9 anos)

Estudos da OMS mostram que o primeiro passo para a transformação é a comunicação e a informação mais atualizada e correta para os profissionais da linha de frente da saúde e, também, para a população, pois com os conhecimentos já existentes bem difundidos, é possível melhorar a reação aos estilos de vidas não favoráveis ${ }^{23}$.

Assim, a saúde, em seu conceito mais amplo e complexo, é construída como produto social, coletiva e individualmente, contando com ações em diversas esferas, desde a individual, passando pelas ações da sociedade até as governamentais, geradas em diversas interfaces.

\section{Movimentos de mudança}

Uma das características verificadas nos dados coletados foram as ações indicando mudanças no estilo de vida ou comportamentos de saúde, ora por problemas de saúde ou orientações médicas e/ou familiares, ora estimuladas pelas perguntas da pesquisadora.

Ultimamente, eu estou comendo mais verduras e legumes. Antigamente eu não comia tanto, eu não gostava. Agora eu passei a comer. [...] por causa da minha alergia eu comecei a melhorar a comida. (Pica-Pau, 12 anos)

Melhorando minha alimentação. [...] melhorar a alimentação, beber bastante água. (Minnie Mouse, 10 anos)

Normalmente, as atitudes que remetem à mudança no estilo de vida são consequências de aprendizados mediante situações vivenciadas. Neste contexto, a dinâmica do empowerment ${ }^{6}$ é flagrante. Estas ações devem ser realizadas em ambientes distintos como escolas, residências, locais de trabalho e demais espaços coletivos $^{6}$, além de ambientes de saúde.

Algumas falas sobre mudança das crianças, vulneráveis a informações que podem guiá-los por caminhos saudáveis por toda vida, remetem a transfor- 
mações no seio familiar, que é considerado o primeiro e principal agente transmissor de comportamentos e estilos de vida ${ }^{24}$ :

Meu avô fumava, só que agora ele parou [...] eu não gosto muito, porque eu acho que faz mal pra nossa saúde. Eu gosto de tomate. Tomate também faz bem, eu como banana, uva, que também faz bem. Como assim, a maioria coisa saudável. (Fiona, 10 anos)

Ações de educação em saúde para crianças devem ser prioritárias nas Políticas Públicas de Saúde, uma vez que a entrada na adolescência é fase crítica com relação à autonomia, afirmação e independência. Se eles têm a oportunidade de desenvolver hábitos saudáveis, poderão ser adultos com uma qualidade de vida melhor.

Muitos alimentos que eu não como. Eu sei que tenho que aprender a comer, mas às vezes, tipo assim, eu não como. (Docinho, 9 anos)

A massificação definida por Freire é o inverso da atitude reconhecida nestas falas. Quando o indivíduo se massifica, perde a capacidade de distinguir o que lhe faz bem ou mal. Mesmo que mudanças possam ser demoradas e dependam de diferentes esferas, é imperativo reconhecê-las como necessárias. Assim, a educação deve ser uma tentativa constante de mudança de atitude ${ }^{8}$.

Compreendendo o corpo como pleno de subjetividade e moldado pela historicidade, como no pensamento de Merleau-Ponty, a consequência destes fatos está nas decisões teóricas e práticas da vida e do conhecimento de cada indivíduo 9 . O escolar empoderado pode decidir o melhor para sua saúde, ingerindo ou fazendo o não saudável, mas prazeroso, em momentos pontuais. No exemplo, sua subjetividade, historicidade e conhecimentos foram usados para tomar tal decisão $0^{25}$.

Dizer não à determinada atitude nociva à própria saúde torna a criança detentora de práticas, mas, sendo criança, este poder passa pelos adultos, conferindo a estes a responsabilidade de guiá-las por caminhos saudáveis.

\section{O brincar}

A ação de brincar é definida como um comportamento complexo e, portanto, apresenta definições variadas para diferentes autores, podendo ser caracterizado como um comportamento que possui um fim em si mesmo, com origem livre, isenta de obrigatoriedade, motivado pelo prazer ${ }^{26}$.

Questões culturais e sociais marcam fortemente as brincadeiras, assim como as características sociais de cada população. Conceitos como o da zona lúdica ajudam a explicar estes aspectos influenciadores do brincar. A zona lúdica é definida como sendo composta por três elementos, quais sejam: a criança, com suas experiências, seus recursos, motivações, pressões e condições sociais que a cercam; o espaço físico, em que está inserida, considerando os brinquedos a que tem acesso; e, por fim, o espaço temporal, que compreende o tempo dedicado à brincadeira e às crenças familiares ${ }^{26}$.

Estudiosos também relacionam o brincar com a imaginação, ligado ao sonhar, ao pensamento e ao simbólico e, ao mesmo tempo, como um instrumento para trabalhar educação de crianças, pois, durante o brincar, elas criam, recriam e se relacionam com o mundo ${ }^{27,28}$.

Observou-se que o brincar foi identificado como integrante das variadas formas de prática de atividade física e considerado comum para as crianças, quando perguntadas sobre quais tipos de atividades físicas poderiam fazer.

Atividade física [...] eu acho que brincar. Brincar de correr? É brincar de correr, de queimada, de três cortes. (Minnie Mouse, 10 anos)

Natação, vôlei, jogar basquete, jogar jogos legais, brincar, correr. (Barbie, 9 anos)

Segundo algumas pesquisas ${ }^{29}$, a atividade física de brincar da criança é influenciada pelo número de irmãos, ou seja, quanto mais irmãos ela tem, mais irá brincar. Este fato está relacionado com a regulação do seu peso corporal, constituindo um fator preventivo da obesida$\mathrm{de}^{29}$. A fala abaixo ilustra o que as pesquisas descrevem:

Nem olho para televisão, só fico brincando porque lá tem muita criança e na minha casa é chato, não tem gente para brincar. (Minnie Mouse, 10 anos)

A família e a escola, por serem os ambientes nos quais a criança pratica a maioria das brincadeiras, devem ser fomentadores dessas atividades não somente como medida preventiva, mas também como forma terapêutica quando já há presença da obesidade ${ }^{28}$. Deve-se considerar, também, que brincadeiras como jogos são utilizados como ferramentas de aprendizagem para diversos temas de saúde ${ }^{30}$.

Ao gerar um paralelo entre a atividade física do adulto e da criança, este entrevistado corroborou para a identificação da brincadeira como uma forma de atividade física:

Correr, se exercitar [...] no caso das crianças brincar e, no caso dos adultos, ir na academia [...] eu acho que só isso. (Cinderela, 10 anos)

Conhecer a criança a partir de seu próprio mundo é a proposta de Merleau-Ponty ${ }^{9}$ e reconhecer nas brincadeiras os sentidos que ela cria e se expressa para com as coisas do mundo pode ser a melhor forma de ajudá-la, mediando o caminho para a construção de uma vida mais saudável.

\section{Conclusão}

Entre as quatro subcategorias analisadas neste artigo, família e escola, saúde como ausência de doença, movimentos de mudança e o brincar, emergiu a necessidade de considerar o escolar como um foco para edu- 
cação em saúde, já que o conhecimento demonstrado por eles sobre vida saudável e ações que os tornam corresponsáveis pela própria saúde foram vastos. A família e a escola como interfaces de geração de hábitos devem ser consideradas aliadas na construção de comportamentos de saúde.

$\mathrm{O}$ aumento do acesso às informações deve ser considerado, pois, permite o empoderamento da criança e proporciona a mudança do pensamento sobre a saúde apenas como oposta à doença, visto sua vulnerabilidade às informações a partir das quais indicam movimentos de alteração em seus ambientes.

Faz-se necessário tornar a educação em saúde uma busca constante de mudança de atitudes e comportamentos, sabendo que, muitas vezes, a repetição será primordial e, em outras ocasiões, formas diferentes de ação deverão ser adotadas. $\mathrm{O}$ incentivo governamental junto aos programas de saúde é importante, mas não o único responsável. $\bigcirc$ profissional de saúde deve compreender que suas ações individuais são capazes de afetar o comportamento de saúde de muitos indivíduos, principalmente quando são crianças, pois em suas interfaces de relacionamentos irão agregar seus conhecimentos aos de outros indivíduos.

As limitações deste estudo devem-se à ocorrência de um único encontro, não sendo possível reproduzi-lo com outros grupos de crianças, considerando-se o tempo estimado para o desenvolvimento do estudo.

Concluiu-se que o enfermeiro, profissional capacitado e atuante em diferentes ambientes, pode ser o mediador destas interfaces e contribuir para a autonomia do escolar na corresponsabilidade para desenvolvimento de hábitos saudáveis mediante ações de educação em saúde.

\section{REFERÊNCIAS}

1.World Health Organization. World Health Statistics 2011: WHO 2011. Geneva (Swi): WHO; 2011.

2.Ministério da Saúde (Br). Secretaria de Vigilância em Saúde, Departamento de Análise de Situação de Saúde. Plano de ações estratégicas para o enfrentamento das doenças crônicas não transmissíveis (DCNT) no Brasil 2011-2022. Brasília (DF): Ministério da Saúde; 2011.

3.Ministério da Saúde $(\mathrm{Br})$. Secretaria de Atenção à Saúde, Departamento de Ações Programáticas Estratégicas. Agenda de compromissos para a saúde integral da criança e redução da mortalidade infantil. Brasília (DF): Ministério da Saúde; 2004.

4.Ministério da Saúde (Br). Secretaria de Gestão Estratégica e Participativa, Departamento de Apoio à Gestão Participativa. Caderno de educação popular e saúde. Brasília (DF): Ministério da Saúde; 2007.

5.Pender NJ, Murdaugh CL, Parsons MA.Health promotion in nursing practice $4^{\text {th }}$ ed. Englewoodcliffs (NJ): Prentice Hall; 2002.
6.Carvalho SR, Gastaldo D. Promoção à saúde e empoderamento: uma reflexão a partir das perspectivas crítico-social pós-estruturalista. Ciência \& Saúde Coletiva [Scielo-ScientificElectronic Library Online]. 2008 [citado em 03 out 2015]. 13:2029-40. Disponível em: http:// www.scielosp.org/pdf/csc/v13s2/v13s2a07

7.Pender N. The Health promotion model manual. [Internet]. [cited in 2015 Aug 30]. Available from: http:// nursing.umich.edu/faculty-staff/nola-j-pender

8.Freire P. Educação como prática da liberdade. $23^{\mathrm{a}} \mathrm{ed}$. Rio de Janeiro: Paz e Terra, 1999.

9.Merleau-Ponty M. Fenomenologia da percepção. São Paulo: Martins Fontes; 1999.

10.Governo Federal (Br). Lei 8.069, de 13 de julho de 1990. Estatuto da Criança e Adolescente. Brasília (Br): Gráfica de Senado Federal; 1990.

11.Biblioteca Virtual em Saúde (BIREME). DEC's Descritores em Ciências da Saúde. [Internet]. [citado em 30 nov 2015]. Disponível em: http://decs.bvs.br/cgi-bin/ wxis1660.exe/decsserver/

12. Ministério da Saúde (Br). Resolução n ${ }^{\circ} 466$, de 12 de dezembro de 2012 [Internet]. Brasília (DF); CNS; 2012. [citado em 30 nov 2015]. Disponível em: http://bvsms.saude.gov.br/bvs/saudelegis/cns/2013/ res0466_12_12_2012.html

13.Bardin L. Análise de Conteúdo. $3^{\mathrm{a}}$ ed. Lisboa (Pt): Edições 70; 2004.

14.Oliveira DC. Análise de conteúdo temático-categorial: uma proposta de sistematização. Rev enferm UERJ. 2008; 16:569-76.

15.Cordazzo STD, Vieira ML. A brincadeira e suas implicações nos processos de aprendizagem e de desenvolvimento. Estudpesqui psicol. [Scielo-ScientificElectronic Library Online] 2007 [citado em 08 nov2013]; 7:89-101. Disponível em: www.revispsi.uerj.br/v7n1/artigos/pdf/ v7n1a09.pdf

16. Wilhelm FA, Lima JHCAD, Schirmer KF. Obesidade infantil e a família: educadores emocionais e nutricionais dos filhos. Psicol Argum. [Scielo-Scientific Electronic Library Online] 2007 [citado em 03 out 2015]; 25(49), 143-54. Disponível em: http://bases.bireme.br/cgi-bin/ wxislind.exe/iah/online/?IsisScript $=$ iah/iah.xis \& sr$\mathrm{c}=$ google $\&$ base $=$ LILACS\&lang $=\mathrm{p} \&$ nextAction $=1$ nk\&exprSearch $=527252$ \&indexSearch $=I D$

17.Seabra AF, Mendonça DM, Thomis MA, Anjos LA, Maia JA. Determinantes biológicos e socioculturais associados à prática de atividade física de adolescentes. Cad Saúde Pública. 2008; 24:721-36.

18.Santos Silva AC, Santos I. Promoção do autocuidado de idosos para o envelhecer saudável: aplicação da teoria de Nola Pender. Texto Contexto Enferm. [Scielo-ScientificElectronic Library Online] 2010 [citado em 05 set 2015]; 19: 745-53. Disponível em: http://www.redalyc. org/articulo.oa?id $=71416100018$

19.Sakraida TJ. Nola J Pender: Health promotion model. In: Tomey AM, Alligood MR. Nursing theorists and their work. $6^{\text {th }}$ ed. St Louis-(Mi): Mosby-Elsevier; 2006. p.452-71. 
20.Abreu AR, Pereira MCR, Soares MTP, Nogueira N. Saúde: $1^{\text {a }}$ Parte. 59-90. [citado em 12 out 2015]; Disponível em: http://portal.mec.gov.br/seb/arquivos/ pdf/livro092.pdf

21.Refrande SM, Silva RMCRA, Pereira ER, Silva MA. Estratégias em saúde da criança: contribuições ao ensino em enfermagem a partir do pensar Merleau-Pontyano. Revista Cubana de Enfermería [Scielo-Scientific Electronic Library Online] 2012 [cited in 2015 oct 12]; 28:156-68. Available from: http://scielo.sld.cu/pdf/enf/ v28n2/enf11212.pdf

22.Guloso, in Dicionário Priberam da Língua Portuguesa. [internet] [citado em 12 out 2015]; Disponível em: http://www.priberam.pt/dlpo/guloso

23. World Health Organization. Prevenção de doenças crônicas um investimento vital. [internet] WHO: Canadá, 2005; [cited in 2015 Mai 25]; Available from: http://www.who.int/chp/chronic_disease_report/contents/en/index.html

24.Seabra AF, Mendonça DM, Thomis MA, Anjos LA, Maia JA. Determinantes biológicos e socioculturais associados à prática de atividade física de adolescentes. Cad Saúde Pública. 2008; 24:721-36.

25.Nóbrega TP. Merleau-Ponty: o filósofo, o corpo e o mundo de toda a gente! In: AnaisXV Congresso Brasileiro de Ciências do Esporte e II Congresso Internacional de Ciências do Esporte; 2007; Recife, Brasil. [internet] [citado em 12 out 2015]; Disponível em: http://www.cbce.org.br/cd/resumos/129.pdf.

26.Hansen J, Macarini SM, Martin GDF, Wanderlind FH, Vieira ML. O brincar e suas implicações para o desenvolvimento infantil a partir da psicologia evolucionista. Rev Bras Crescimento Desenvolv Hum. 2007; 17:133-43.

27.Gomes TP, Castro GM. Brincar e desenvolvimento infantil: uma análise reflexiva. [internet] 2010; [citado em 08 out 2015]; Disponível em: www.ufpi.br/subsiteFiles/ppged/arquivos/files/.../GT_08_04_2010.pdf

28.Pontes TE, Costa TF, Marum ABRF, Brasil ALD, Taddei JAAC. Orientação nutricional de crianças e adolescentes e os novos padrões de consumo: propagandas, embalagens e rótulos. Rev Paul Pediatr. [Scielo-ScientificElectronic Library Online] 2009 [citado em 08 nov2013]; 27:99-105. Disponível em: http://www. scielo.br/pdf/rpp/v27n1/15.pdf 98

29. Guimarães LV, Barros MBA, Martins MSAS, Duarte EC. Fatores associados ao sobrepeso em escolares. Rev Nutr. [Scielo-ScientificElectronic Library Online] 2006 [citado em 08 nov 2015]; 19:5-17. Disponível em: http://repositorio.unb.br/handle/10482/12915

30.Silva JM, Pagliuca LMF, Carvalho AT, Oliveira MG, Almeida PC. Conhecimento de escolares acerca de pessoa com deficiência: jogo de labirinto na promoção da saúde. Revenferm UERJ. 2015; 23:254-9. 